\title{
World Class Manufacturing (WCM) MOdel AS A TOOL FOR COMPANY MANAGEMENT
}

\author{
Peter Poor, Marek Kocisko \& Radoslav Krehel
}
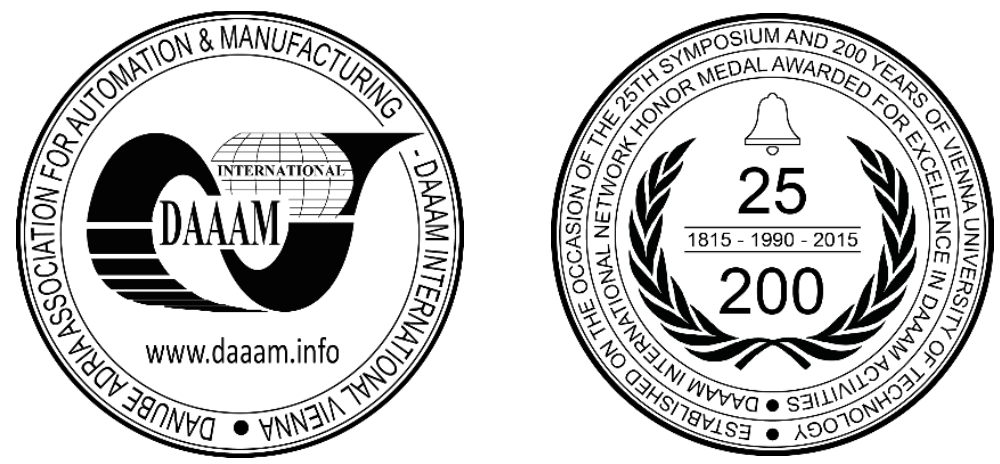

This Publication has to be referred as: Poor, P[eter]; Kocisko, M[arek] \& Krehel, R[adoslav] (2016). World Class Manufacturing (WCM) Model as a Tool for Company Management, Proceedings of the 27th DAAAM International Symposium, pp.0386-0390, B. Katalinic (Ed.), Published by DAAAM International, ISBN 978-3-902734-08-2, ISSN 1726-9679, Vienna, Austria

DOI: $10.2507 / 27$ th.daaam.proceedings.057

\begin{abstract}
Rapid pace of world economy development is forcing businesses to adapt to conditions of global competition and find ways of successful application in an environment of constant change. In current business conditions in predominance of demand and open market the question of gain and apply a competitive advantage is critical for establishment and operation of all types of enterprises. Basic requirements of competitiveness are consistent customer orientation, reliability, and quality management. World Class Manufacturing [WCM] is collective term for most effective methodologies and techniques to realize products of consistent high quality, delivery On Time In Full amount ordered and products at lowest possible cost level. Companies engaging in World Class Manufacturing strategies focus on improving operations, strive to eliminate waste and create lean organizations. This often results in higher productivity. But these companies also focus on speed of total throughput from order capture through delivery setting new standards for delivery without heavy dependence on inventory (Muda, Hendry, 2002). This paper deals with use of WCM (World Class Manufacturing) model and its use in company management.
\end{abstract}

Keywords: WCM; World Class Manufacturing; company; management; industry.

\section{Introduction}

World Class Manufacturing system is primarily based on a comprehensive Japanese management system called Kaizen. These method improvements in production, increasing quality and flexibility are described in book by Mr. Masaaki Imai. KAIZEN is moving forwards by focusing on production process, unlike western thinking oriented to innovation and results. Before oil crisis in 1980s, world industry development of new technologies and innovations has paid off, but after this event in new situation, where prices for manufacturing resources, quality demands also demands for faster introduction of new products increased, and thus western market was forced to pressure competition resort to Japanese strategy (Lind, 2001).

World Class Manufacturing is an integrated system which improves processes and quality, reduces cost and with increased flexibility fulfils customer expectations. This system is based on 10 pillars of activities and 10 managerial 
pillars. It is a very convenient program in terms of high sophistication. Globalization and competition coming from lowcost countries brings great challenge for industrial production. Only the strongest and most flexible companies can survive. To become the best, we must constantly improve performance and results, we need to strengthen relationships with suppliers and partners. WCM system is for now a great challenge for the future.

The aim is to reach world-class level under conditions of setting these ambitious goals:

- Quality

- Cost

- Delivery

To achieve the highest quality, it is necessary to achieve zero defects, and becoming the largest competition in the world. Costs must be reduced by at least $30 \%$ during the next 3 years. And to fulfil the third objective running time according to the needs of customers must be to shortened. All these goals can be met only through the involvement of people, in this case, company employees. It is necessary to ensure their development and standardization. Only World Class Manufacturing is the proper key to success. The main aspects of all employees, loss and downtime for completeness and also standards methods.

If structure of the system is divided into parts, then we can specify the possibility of reducing incremental costs. First such element is the workplace organization using methods of industrial engineering at a concentration on productivity in order to achieve zero losses. Second element is achieving quality using method of total quality control focus on improving quality in order achieving zero defects. Third important element is fulfilment of maintenance methods concentrating on technical efficiency with the result of achieving zero downtime. The last element is self logistics using "just in time", focus is on level of services with the aim of zero inventory. When properly connected all components of employee involvement, then company creates value and achieves high Customer Satisfaction.

\subsection{Main principles of WCM according to (Flynn, Schroeder, Sakakibara, and Bates, 1997):}

- World Class Safety is essential to achieving World Class Performance

- WCM Leaders encourage and require creation of and adherence to standards

- World Class Companies are becoming the voice of customer "heart / engine" race

- WCM will not accept any loss (goal is always zero: injuries, errors Supply \& quality stock, downtime)

- Consistent use of WCM methodology guarantees the elimination of losses

- World Class race are any abnormalities immediately visible

- WCM takes place directly in workplace, in the process, not in the office

- WCM learn best through team's use of techniques / methods

- WCM strength comes from involvement of people

- World Class companies collect energy from its own successful solutions problems, crises

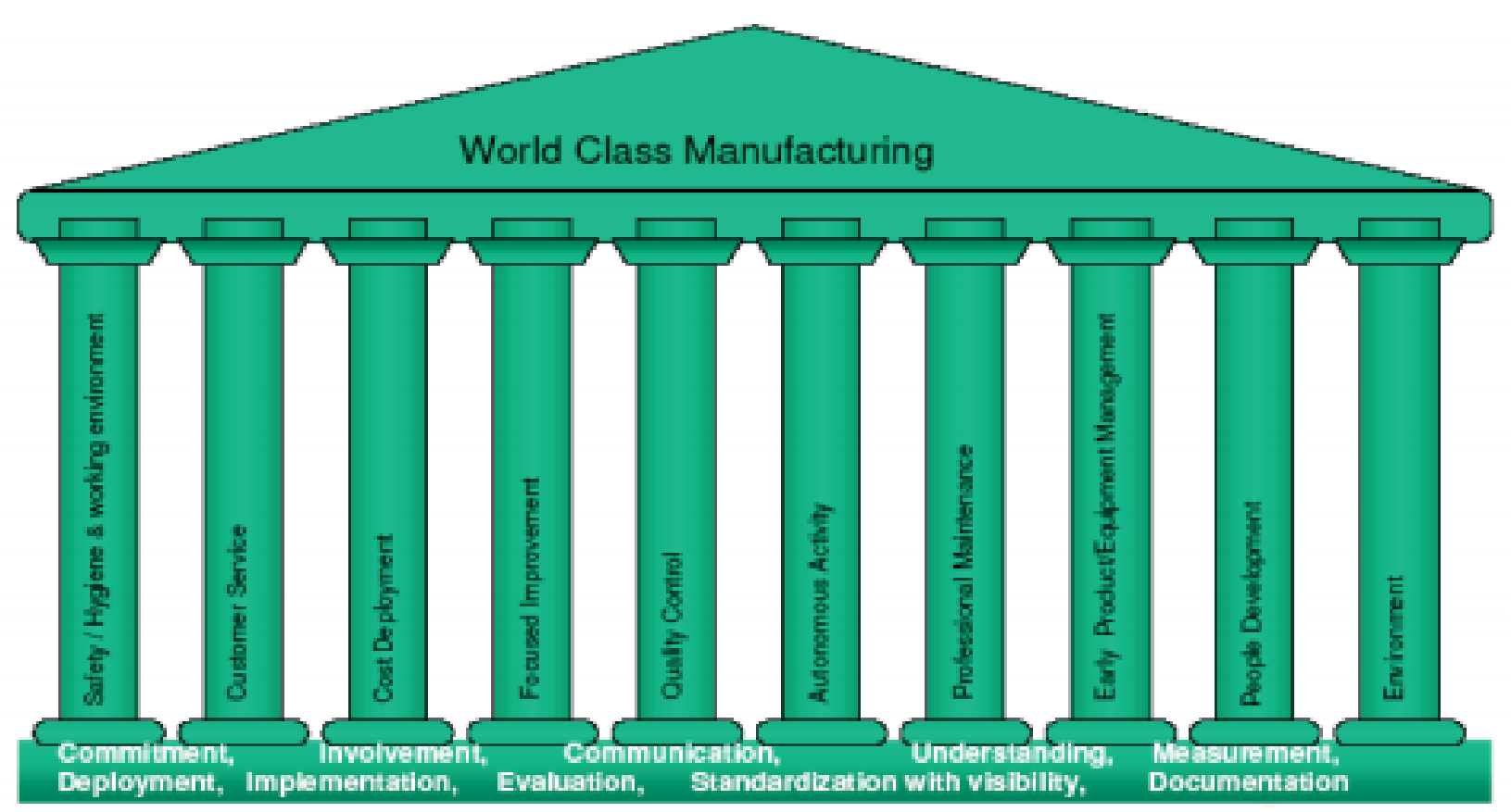

Fig. 1. WCM pillars 


\subsection{WCM basic tools}

1) Prioritization - Organization of importance, identify important issues. They include deployment cost analysis, Pareto diagrams, stratification, ABC Classification for targeted distribution of machines according to their importance in process, QA matrix to identify losses, safety matrix to identify work-related injuries, value stream maps for cost distribution in the process and point mapping of machine failures

2) Systematization and logic - is simply identifying where one problem

3) A description of the problem with sketches - helps to understand the problem

4) $5 \mathrm{~W}+1 \mathrm{H}$ with $5 \mathrm{G}$ principles - simple questions for understanding problems, (What, When, Where, Who, Which, How) regarding the resulting accident $5 \mathrm{G}$ principles are then used to address possible remedies of an accident 5) Root cause analysis - identifying the cause of a graph causes and action or method 5Why), which is considered sufficient quantity questions to reveal the real causes

6) Visualization - description of phenomena using images and detail, determines what it is hidden behind the problem

7) The way to teach people - "a way to teach people to" search for hidden problems, in a way fault-finding in humans, determining whether he knows correctly process works or how to react in case of a problem.

\section{Research goals on WCM implementation into manufacturing company}

\subsection{Research Objectives}

Research objectives are focused on management organization WCM model:

- Implementation of WCM model in the organization,

- Set the entire management system of values and rules of the organization (vision, goals ...)

- Developing an organizational structure,

- $\quad$ Resource management, processes and performance

WCM management in organization includes in particular the overall system configuration management, values and rules of the organization, organizational structure adjustment, resource management, processes and performance. It is a cross-sectional area, are used in her methods of strategic management methods in the area of quality and management efficiency.( Oliver N, Delbridge R, Jones D, Lowe J., 1994)

New management concepts are based on process approach, which is a fundamental principle of continuous improvement of business processes and applied in enterprises as process management. Process management is a form of governance that systematically identifies business processes and their attributes, creating conditions for their efficient operation, coordination, measurement and continuous improvement, resulting in a quality product integrating customer requirements and business strategy.

The object of research of this article is finding representation of individual roles in teams in manufacturing companies in middle and top management. The aim of research is to describe the various staff positions in selected teams.

\subsection{Research plan}

Research Plan will be divided and implemented in two steps:

I. Finding teamwork, which take the role of workers in work teams,

II. Rating the performance of individual work teams

3. Detailed research on WCM model use as a tool for company management

3.1. Diagnostic tools used in the research:

- Questionnaire teamwork (Belbin): For research purposes we will be using a diagnostic tool developed by R. M. Belbin and collective. Methodology - the test consists of seven sections - questions and will be completed by respondents. Each issue will may have eight different answers (claims) and 10 points. Respondents will be selected from eight answers those most characteristic of them and describe their behavior in the team. These points can be assigned to several descriptions. In extreme cases points may be divided among all the claims, or may be assigned any of 10 points to the only claim in the part. It is recommended to avoid this extreme. Points are marked in the box next to sentence.

- Evaluation - points will be entered in the evaluation table.

- Interpretation - The highest score is a team role, where you can most benefit from your team. The second highest score indicates Team roles that can perform well when the smaller group needs your preferred role. Two lowest score indicates role group, you do not like to refer to your weaker points. Instead, however, to 
work towards improving them, it is preferable to seek together with my colleagues opposite tendency of behaviour in the team, with a tendency to hold also the roles that you are complementary. Ideally, the team includes representatives of all these roles, mutually recognizing and utilizing their strengths teamwork.

- Questionnaire Rating performance: This research group will be used questionnaire for rating performance. The second questionnaire aims to team members when their supervisor (Pillar leader) evaluates. The questionnaire contains five performance factors:

- Flexibility

○ Reliability

○ Theoretical knowledge

○ Quality (work passing)

- Quality (performance dates) of work with eight team roles (Implementer Coordinator, strategy, ideas Seeker, Seeker resources critic evaluator team builder, Finisher).

This questionnaire evaluates performance of subordinates in terms of five factors. The answer is indicated by circling the appropriate number on the scale, where 1 is maximum negative and positive assessment than 9 employee in these factors. Numbers 2-8 are intermediate stages, reflecting the greater or lesser inclination to one of the extreme points.

\section{Target group and sampling}

First task is to evaluate the results of the questionnaire Belbin team roles according to the research group teams. The tendency of individual employees to team roles as well as representation roles within the team (pillars). The second task is to measure the performance of team members of five factors.(Vollman, Berry, Whybark, 1997) The target group is aimed at members of middle and senior management.

\subsection{Test Conditions}

Through the approval from organizational structure of project organization and WCM Director of the company personnel department issued an internal notice - Appointment of teams. The questionnaires were distributed by mail from Human Resources department:

- Questionnaire dealing with teamwork (Belbin) was sent to team members and team leader,

- Questionnaire dealing with rating the performance was sent to managers and leaders of individual pillars.

Questionnaires were coded by numbers to guarantee the anonymity of respondents.

\section{Conclusion}

The aim of this paper was to introduce WCM model as a tool for company management. Role within team can rarely be identified by characteristic features, or outward appearance. This was one of the reasons we chose a powerful diagnostic tool for investigation of various team roles - Belbin teamwork questionnaire. It was also necessary to track the performance of a work team. Therefore questionnaire rating the performance was used. Also we needed to specify the target group according to selected criteria. This article is only the beginning, we will continue in the research and you can read the results. in our future articles, thatswhy the results may not be expected soon. We are working on this research and we will publish our results in our next articles.

\section{Acknowledgments}

This paper was created with the subsidy of the project $n^{\circ} \mathrm{K}-14-008-00$.

\section{References}

[1] Oliver N, Delbridge R, Jones D, Lowe J. World class manufacturing: Further evidence in the Lean production debate1. British Journal of Management. 1994 Dec 1;5(s1):S53-63.

[2] Flynn, B.B., Schroeder, R.G., Flynn, E.J., Sakakibara, S. and Bates, K.A., 1997. World-class manufacturing project: overview and selected results. International Journal of Operations \& Production Management, 17(7), pp.671-685.

[3] Lind, J., 2001. Control in world class manufacturing-A longitudinal case study. Management Accounting Research, 12(1), pp.41-74.

[4] Lau, R.S., 1996. Strategic flexibility: a new reality for world-class manufacturing. SAM Advanced Management Journal, 61(2), p.11. 
[5] Thomas E.. Vollmann, William L.. Berry and Whybark, D.C., 1997. Manufacturing planning and control systems. Irwin/McGraw-Hill.

[6] Voss, C. and Blackmon, K., 1996. The impact of national and parent company origin on world-class manufacturing: findings from Britain and Germany. International Journal of Operations \& Production Management, 16(11), pp.98-115.

[7] Muda, S. and Hendry, L., 2002. Proposing a world-class manufacturing concept for the make-to-order sector. International Journal of Production Research, 40(2), pp.353-373.

[8] Al Falah, K., Zairi, M. and Moneim Ahmed, A., 2003. The role of supply-chain management in world-class manufacturing: An empirical study in the Saudi context. International Journal of Physical Distribution \& Logistics Management, 33(5), pp.396-407.

[9] DeFilippo, J.S., 1997. World-class manufacturing in Chengdu: a case study on China's first aviation joint venture. International Journal of Technology Management, 13(5-6), pp.681-694.

[10] Kodali, R., Sangwan, K.S. and Sunnapwar, V.K., 2004. Performance value analysis for the justification of worldclass manufacturing systems. Journal of Advanced Manufacturing Systems, 3(01), pp.85-102.

[11] Subramanian, A. \& Sun, H.: A Model for Value Chain Integration in a Vertically Integrated Design and Manufacturing Firm

[12] Rakyta, M.; Fusko, M.; Haluska, M. \& Grznar, P.: Maintenance Support System for Reconfigurable Manufacturing Systems

[13] Radzevich, S. P., \& Krehel', R. (2011). Application priority mathematical model of operating parameters in advanced manufacturing technology. International Journal of Advanced Manufacturing Technology,56(5-8), 835840 .

[14] Novotný, L., Abreu, H.,F.,G., Miranda, H.,C., M. Beres, M.: Simulations in multipass welds using low transformation temperature filler material. Science and Technology of Welding and Joining, Vol. 21, no. 8, pp 680 - 687, 2016

[15] Hendry, L. C. (1998). Applying world class manufacturing to make-to-order companies: Problems and solutions. International Journal of Operations \& Production Management, 18(11), 1086-1100

[16] Kucerova, M.; Mlkva, M.; Paulova, I.: APPLYING PRINCIPLE OF CUSTOMER FOCUS IN BUSINESS PRACTICE. Annals of DAAAM \& Proceedings; 2010, p695 